\title{
The Synthesis of $\mathrm{NiO} / \mathrm{TiO}_{2}$ Heterostructures and Their Valence Band Offset Determination
}

\author{
Z. H. Ibupoto, ${ }^{1}$ M. A. Abbasi, ${ }^{1}$ X. Liu, ${ }^{2}$ M. S. AlSalhi, ${ }^{3,4}$ and M. Willander ${ }^{1}$ \\ ${ }^{1}$ Physical Electronics and Nanotechnology Division, Department of Science and Technology, Campus Norrköping, Linköping University, \\ 60174 Norrköping, Sweden \\ ${ }^{2}$ Department of Physics, Chemistry \& Biology (IFM), Linköping University, 58183 Linköping, Sweden \\ ${ }^{3}$ Physics and Astronomy Department, College of Science, King Saud University, P.O. Box 2455, Riyadh 11451, Saudi Arabia \\ ${ }^{4}$ Research Chair for Laser Diagnosis of Cancer, King Saud University, P.O. Box 2455, Riyadh 11451, Saudi Arabia
}

Correspondence should be addressed to Z. H. Ibupoto; zafar.hussain.ibupoto@liu.se

Received 25 October 2013; Revised 5 January 2014; Accepted 6 January 2014; Published 10 February 2014

Academic Editor: Chunyi Zhi

Copyright (C) 2014 Z. H. Ibupoto et al. This is an open access article distributed under the Creative Commons Attribution License, which permits unrestricted use, distribution, and reproduction in any medium, provided the original work is properly cited.

\begin{abstract}
In this work, a heterojunction based on p-type $\mathrm{NiO} / \mathrm{n}$-type $\mathrm{TiO}_{2}$ nanostructures has been prepared on the fluorine doped tin oxide (FTO) glass substrate by hydrothermal method. Scanning electron microscopy (SEM) and X-Ray diffraction techniques were used for the morphological and crystalline arrays characterization. The X-ray photoelectron spectroscopy was employed to determine the valence-band offset ( $\mathrm{VBO}$ ) of the $\mathrm{NiO} / \mathrm{TiO}_{2}$ heterojunction prepared on $\mathrm{FTO}$ glass substrate. The core levels of $\mathrm{Ni} 2 \mathrm{p}$ and Ti $2 \mathrm{p}$ were utilized to align the valence-band offset of p-type $\mathrm{NiO} / \mathrm{n}$-type $\mathrm{TiO}_{2}$ heterojunction. The valence band offset was found to be $\sim 0.41 \mathrm{eV}$ and the conduction band was calculated about $\sim 0.91 \mathrm{eV}$. The ratio of conduction band offset and the valence-band offset was found to be 2.21 .
\end{abstract}

\section{Introduction}

Recently, the fabrication and the engineering of nanostructures based on metal oxides have drawn effective attention of the researchers due to their specific electronic and optoelectronic features and more practical applications in the industry and technology [1]. Among the various metal oxides, the nanostructures of titanium dioxide $\left(\mathrm{TiO}_{2}\right)$ are more popular because of their uniqueness and attractive properties in optics, electronics, photochemistry, and biology in addition to its usability in the fabrication of photovoltaic devices [24], lithium ion batteries [5], dye-sensitized solar cells [6, 7], and photocatalysts [8-15]. Different methods have been used to enhance the photocatalysts properties of titanium dioxide such as $\mathrm{TiO}_{2}$-carbon hybrids and doping of $\mathrm{TiO}_{2}$ with metals and nonmetals has also significant contribution on the photocatalysts properties of titanium dioxide nanomaterial [10-12].

Several growth techniques have been used for the synthesis of one dimensional $\mathrm{TiO}_{2}$ nanostructures such as hydrothermal [16], template synthesis [17, 18], electrochemical etching $[19,20]$, chemical vapor deposition [21], and sol-gel process $[22,23]$. Among above mentioned methods, the hydrothermal technique is highly promising because of its low temperature, simple, cost effectiveness, and the environment friendly advantages.

Besides titanium dioxide, nickel oxide $(\mathrm{NiO})$ is p-type semiconductor material and is widely used in different applications such as transparent conductive films [24], electrochromic devices [25], as a potential candidate in the chemical sensors [26, 27]. $\mathrm{NiO}$ exhibits a wide bandgap of 3.6$4.0 \mathrm{eV}$ at room temperature; thus, $\mathrm{NiO}$ is considered transparent in the visible light region. Moreover, $\mathrm{NiO}$ is largely used as a cocatalyst with different $n$-type semiconductors due its high p-type concentration, high hole mobility, and low cost [28]. The existence of $\mathrm{NiO}$ enhances the separation of electron and hole pairs via electric junction field and also promotes the interfacial charge transfer [29-31]. NiO nanostructures can be synthesized by sputtering [32], chemical vapor deposition $[33,34]$, hydrothermal method [27], and the sol-gel method 

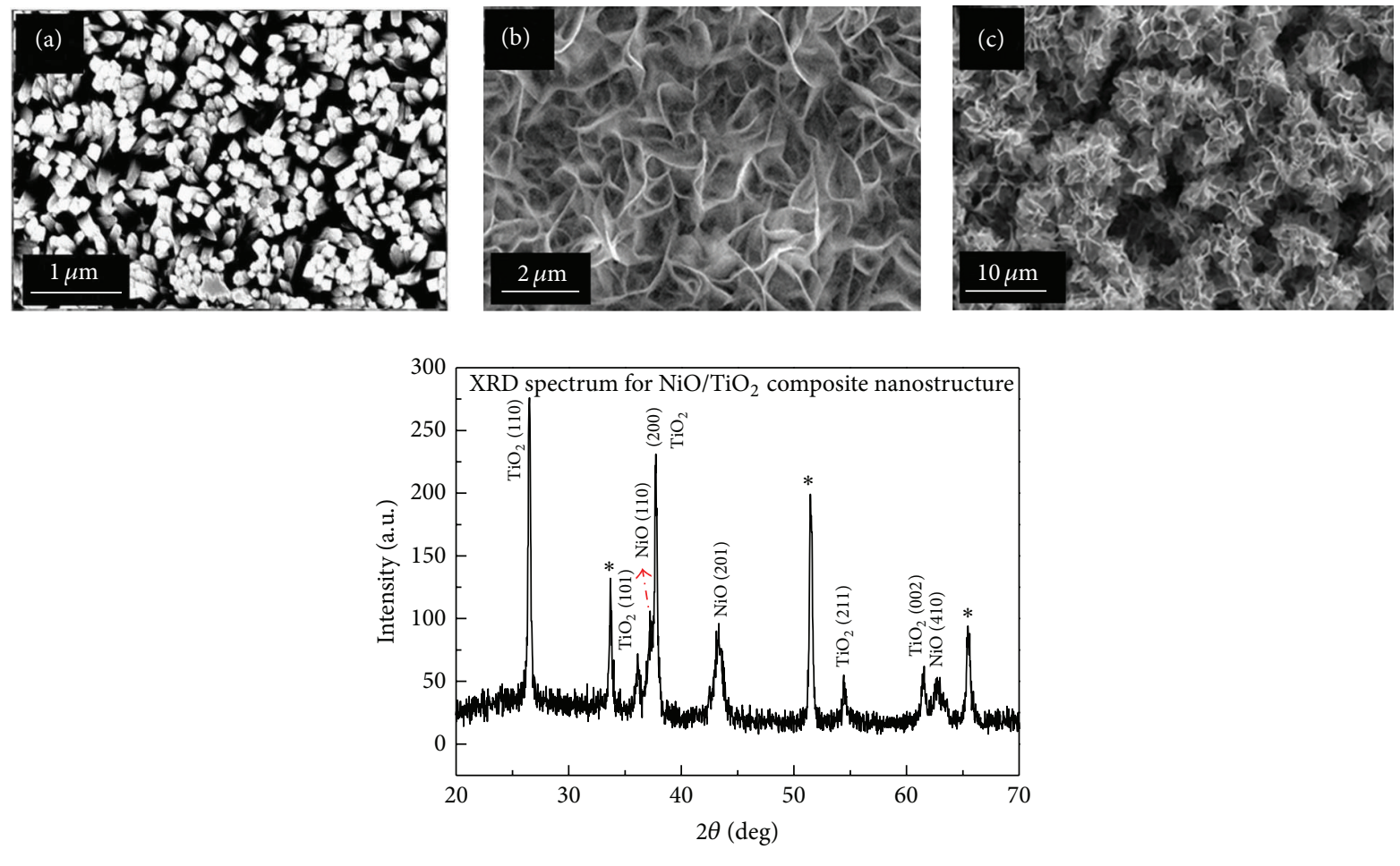

* FTO

(d)

FIgURE 1: (a) The SEM image of pure $\mathrm{TiO}_{2}$ nanorods, (b) SEM image of pure NiO nanostructures, (c) SEM image of heterostructures of p-type $\mathrm{NiO} /$ n-type $\mathrm{TiO}_{2}$ nanostructures, and (d) XRD of the composite nanostructures.

$[35,36]$. The hydrothermal method for the synthesis of $\mathrm{NiO}$ nanostructures is relatively more favourable due to its benign features and simplicity.

After surveying the literature it is known that the valenceband offset (VBO) of $\mathrm{NiO} / \mathrm{ZnO}$ heterojunction has been investigated by few researchers. The growth pattern in their research was as follows: in some cases $\mathrm{NiO}$ was used as substrate and $\mathrm{ZnO}$ as the epitaxial layer $[37,38]$. However in several cases $\mathrm{NiO} / \mathrm{ZnO}$ based light emitting diodes, $\mathrm{ZnO}$ was used as substrate and $\mathrm{NiO}$ as the epitaxial layer [39]. The valence-band offset of many heterojunctions determined by XPS is closely linked to the process of growth of heterostructures [40]. To date there is no report about the determination of valence-band offset of $\mathrm{NiO} / \mathrm{TiO}_{2}$ heterostructures.

In the present work, the fabrication and the design of $\mathrm{TiO}_{2}$ and $\mathrm{NiO}$ heterostructures are followed by hydrothermal method. Moreover, the valence-band offset (VBO) of $\mathrm{NiO} / \mathrm{TiO}_{2}$ heterojunction is measured by XPS technique. The structural characterization of fabricated heterostructures was determined by scanning electron microscopy (SEM) and Xray diffraction $(\mathrm{XRD})$ techniques.

\section{Experimental Section}

The growth process of the presented $\mathrm{p}-\mathrm{n}$ junction based on $\mathrm{TiO}_{2}$ and $\mathrm{NiO}$ nanostructures on the fluorine doped tin oxide (FTO) glass substrate by hydrothermal method was as follows. Firstly, a commercially available and cleaned FTO substrate was used for the synthesis of $\mathrm{TiO}_{2}$ and $\mathrm{NiO}$ nanostructures. In a typical process $1 \mathrm{~mL}$ of TTIP, $20 \mathrm{~mL}$ of $37 \%$ hydrochloric acid, and $40 \mathrm{~mL}$ of deionized water were mixed at constant stirring for 30 minutes. The growth solution was transferred into Teflon vessel of $125 \mathrm{~mL}$ capacity and it was sealed in autoclave and kept in preheated oven at $110^{\circ} \mathrm{C}$ for 12 hours. Afterwards, the $\mathrm{TiO}_{2}$ nanostructures grown FTO substrate was washed with the deionized water and dried at room temperature. $\mathrm{NiO}$ nanostructures were grown on the $\mathrm{TiO}_{2}$ nanostructures by hydrothermal method using equimolar concentration of $(0.1 \mathrm{M})$ nickel chloride hexahydrate and hexamethylenetetramine and the growth solution was letf at $95^{\circ} \mathrm{C}$ for 4-6 hours in preheated electric oven. After the completion of growth time, the heterostructures were washed with the deionized water and dried with the flow of nitrogen gas at room temperature. Then heterostructures were annealed at $450^{\circ} \mathrm{C}$ for the complete conversion of $\mathrm{Ni}(\mathrm{OH})_{2}$ nanostructures into $\mathrm{NiO}$ crystalline phase. The structural characterization was performed by scanning electron microscopy and X-ray diffraction and the core levels and valence-band (VB) spectra of the prepared sample were measured by X-ray photoelectron spectrometer (XPS, Thermo ESCALAB 250) using a $1486.6 \mathrm{eV}$ Al K $\alpha$ source. All XPS spectra were measured by the $\mathrm{C} 1 \mathrm{~s}$ peak $(284.8 \mathrm{eV})$ as a reference substance in order to compensate the charge effect. 


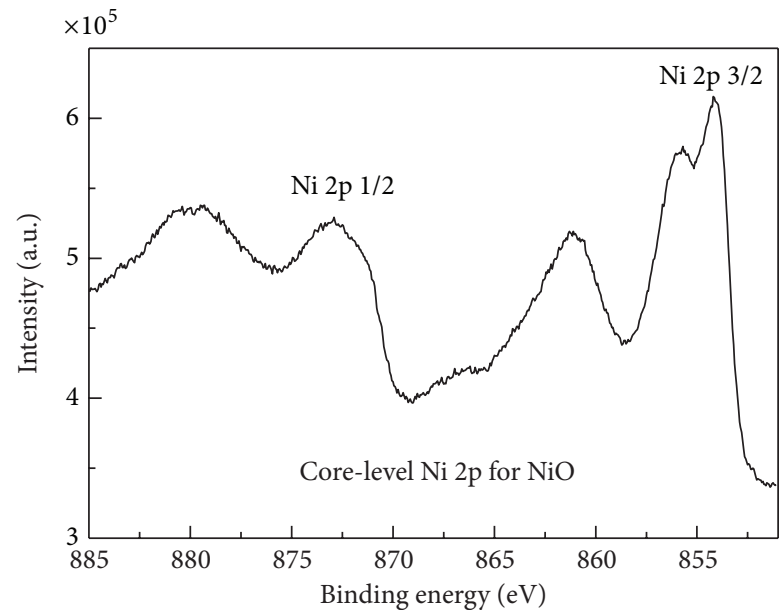

(a)

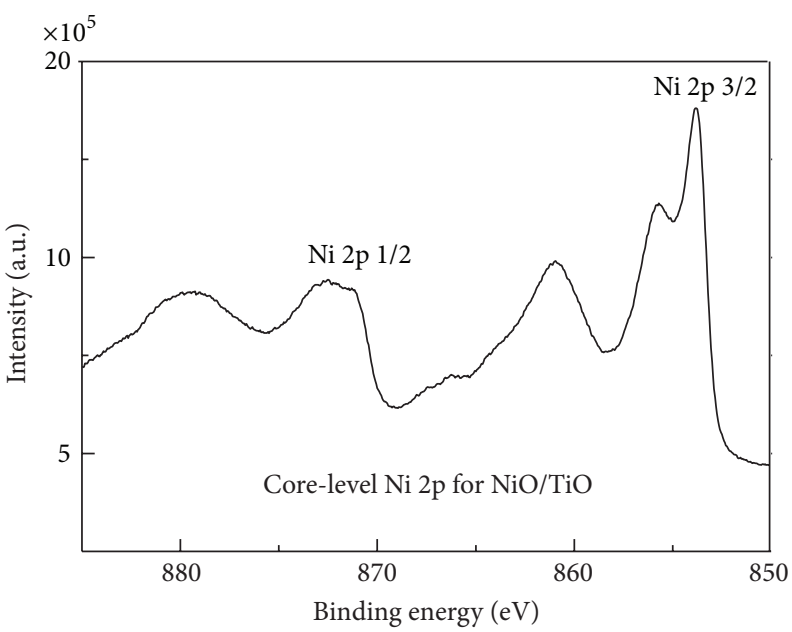

(c)

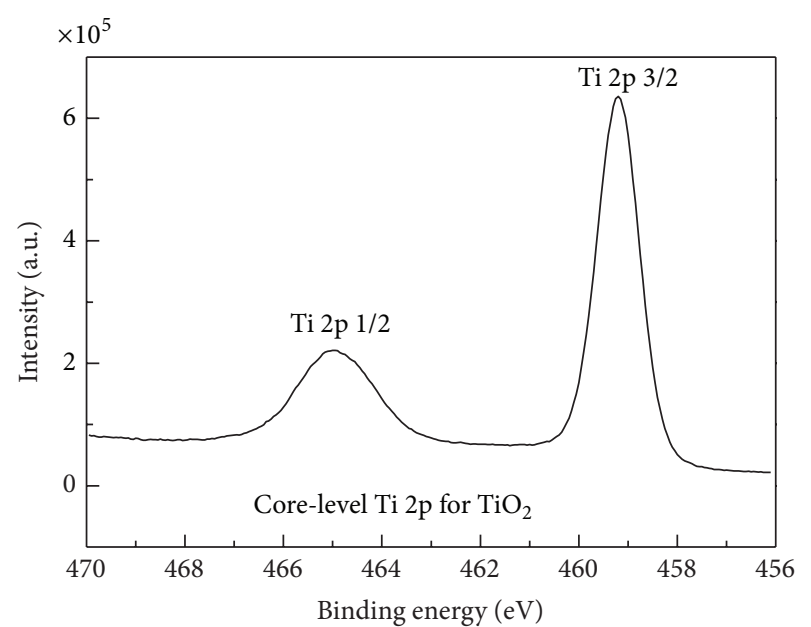

(b)

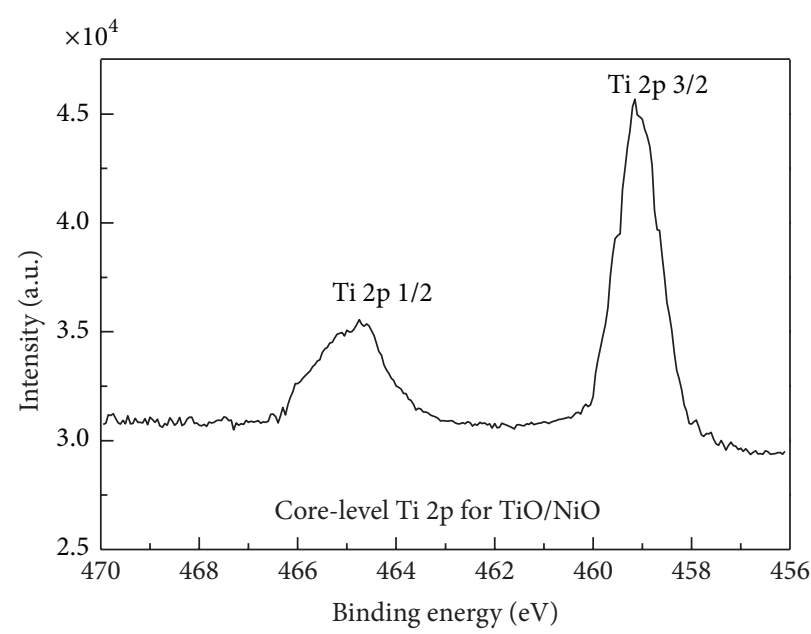

(d)

Figure 2: The XPS measurement for the calculation of valence-band offset of the developed heterojunction of $\mathrm{p}$-type NiO/n-type $\mathrm{TiO}{ }_{2}$ nanostructures, (a) $\mathrm{Ni} 2 \mathrm{p}$ spectrum of pure $\mathrm{NiO}$, (b) $\mathrm{Ti} 2 \mathrm{p}$ spectrum of pure $\mathrm{TiO}_{2}$, (c) $\mathrm{Ni} 2 \mathrm{p}$ spectrum of heterostructures, and (d) $\mathrm{Ti} 2 \mathrm{p}$ spectrum of heterostructures.

\section{Results and Discussion}

3.1. The Structural Characterization of p-Type NiO/n-Type $\mathrm{TiO}_{2}$ Heterostructures. A typical SEM image of $\mathrm{TiO}_{2}$ nanostructures grown on FTO glass substrate by hydrothermal growth technique is shown in Figure 1(a). It can be seen that nanostructures are dense and perpendicular to the substrate. The average diameter and length of nanostructures are $100 \mathrm{~nm}$ and $500 \mathrm{~nm}$, respectively. Figure 1(b) shows the SEM image of $\mathrm{NiO}$ nanostructures and it can be observed that the nanostructures are like a porous structure. Figure 1(c) shows the composite structures of $\mathrm{NiO} / \mathrm{TiO}_{2}$ nanostructures and from the presented image it is clear that almost top surface of $\mathrm{TiO}_{2}$ nanostructures is fully covered with the nanostructures of $\mathrm{NiO}$.

Figure $1(\mathrm{~d})$ shows the diffraction pattern of $\mathrm{NiO} / \mathrm{TiO}_{2}$ nanostructures grown on the FTO glass substrate at room temperature. All the diffraction peaks could be assigned to rutile phase of $\mathrm{TiO}_{2}$ and well match to the JCPDS (card number 211276). The intense (002) peak reflects that the preferred orientation of $\mathrm{TiO}_{2}$ nanorods is along the (001) direction. However, some peaks of $\mathrm{NiO}$ are also shown in Figure 1(d) and it can be seen that the sample is composed of $\mathrm{NiO}$ and $\mathrm{TiO}_{2}$ nanostructures. Some diffraction peaks also appeared for FTO glass substrates which are indicated by star sign.

3.2. The Calculation of Band Offset by XPS Measurement. Figure 2 shows the core level (CL) spectrum of spin-orbit splitting of Ti $2 p$ and Ni $2 p$ peaks. The CL spectrum of Ni $2 p 3 / 2$ is represented by Figure 2(a) and two dominant peaks are found at $854.13 \mathrm{eV}$ and $855.78 \mathrm{eV}$ which are mainly concerned the Ni-O linkages. Figure 2(b) shows that the $\mathrm{Ti}$ $2 \mathrm{p} 3 / 2$ peak at $458.3 \pm 0.1 \mathrm{eV}$ is indexed to the $\mathrm{Ti}-\mathrm{O}$ bond and the peak at $464.0 \pm 0.1 \mathrm{eV}$ is assigned to the Ti $2 \mathrm{p} 1 / 2$ oxidation 


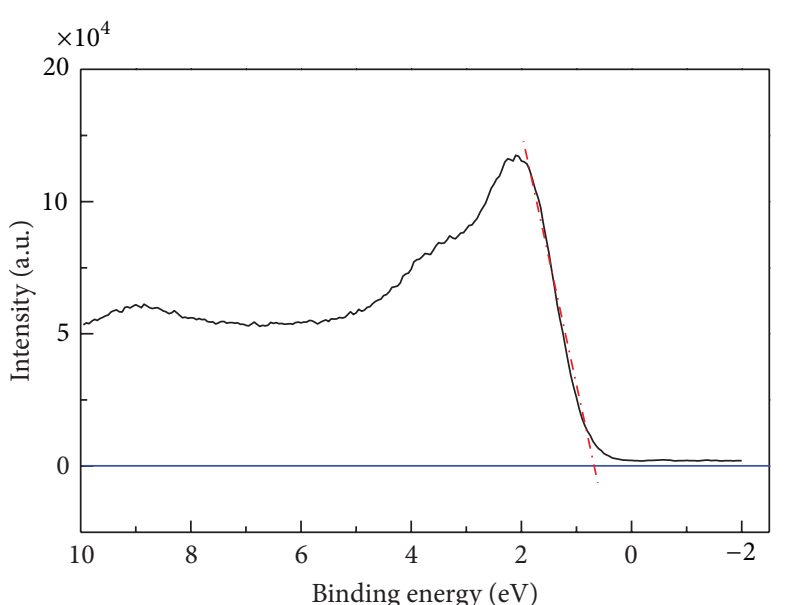

- VB spectra for $\mathrm{NiO}$

(a)

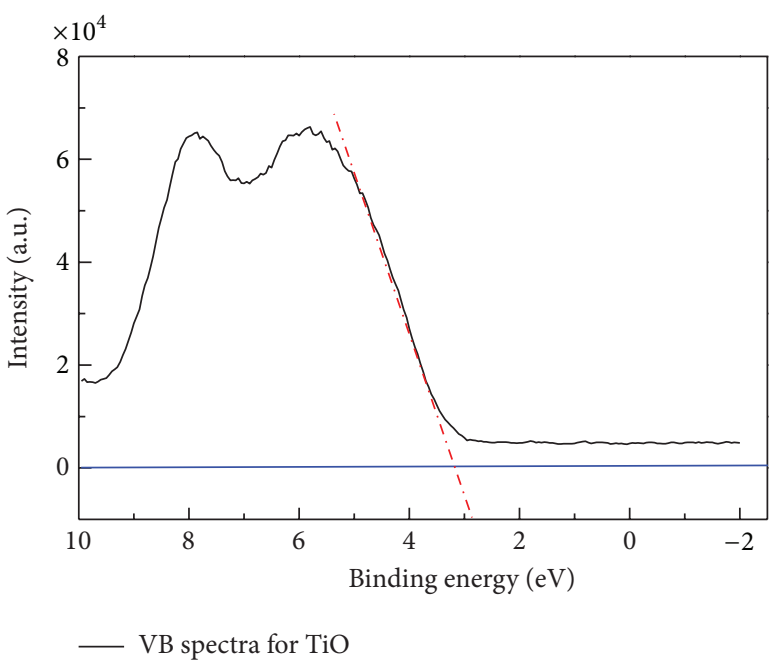

(c)

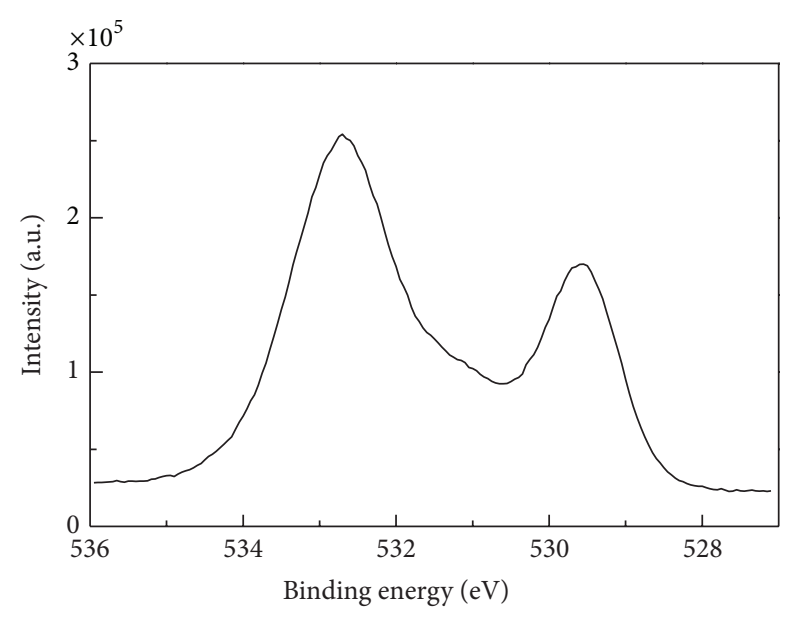

- $\mathrm{O} 1 \mathrm{~s}$ for pure $\mathrm{NiO}$

(b)

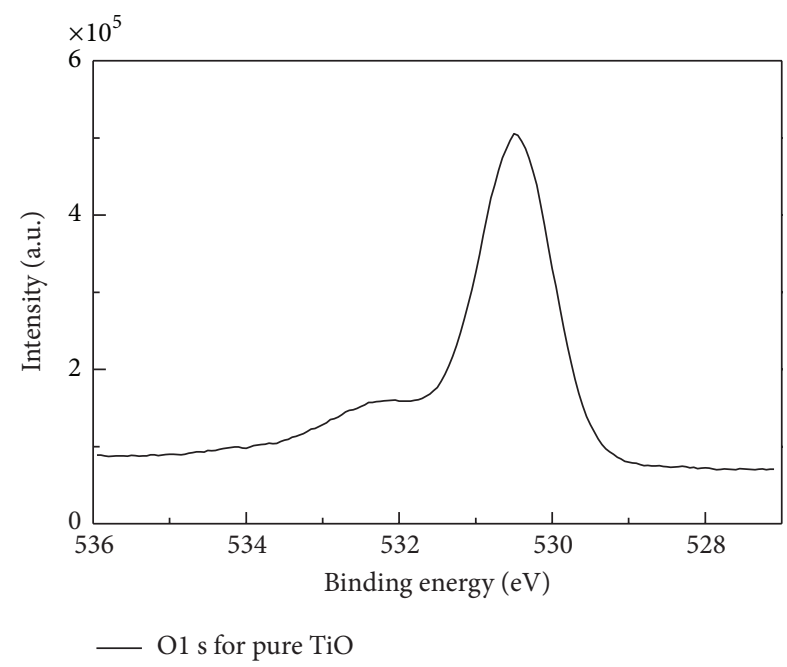

(d)

Figure 3: (a) VB spectrum of $\mathrm{NiO}$, (b) $\mathrm{VB}$ spectrum of $\mathrm{TiO}_{2}$, (c) $\mathrm{O} 1 \mathrm{~s}$ spectrum of $\mathrm{NiO}$, and (d) $\mathrm{O} 1 \mathrm{~s}$ spectrum of $\mathrm{TiO}_{2}$.

state [41-43]. Both measured both peaks are symmetric and the FWHM of Ti $2 p 3 / 2$ is found to be $1.1 \mathrm{eV}$ that is matching with the reported values, and it is attributed to the defect free $\mathrm{TiO}_{2}$ synthesized by sol-gel method (110) $[42,43]$. The nickel $2 \mathrm{p}$ and $\mathrm{Ti} 2 \mathrm{p}$ peaks in the $\mathrm{NiO} / \mathrm{TiO}_{2}$ heterostructures are shown in Figures $2(\mathrm{c})$ and $2(\mathrm{~d})$. It has been indicated that the measured peaks are symmetric relative to that of information obtained from the pure samples of $\mathrm{NiO}$ and $\mathrm{TiO}_{2}$, the change in $\mathrm{Ni} 2 \mathrm{p}$ peak is observed from the value $0.3 \mathrm{eV}$ to the binding energy value of $853.839 \mathrm{eV}$ and the Ti $2 \mathrm{p}$ $3 / 2$ is changed from the 0.056 to $459.16 \mathrm{eV}$. The valence-band (VB) spectrum of $\mathrm{NiO}$ and $\mathrm{TiO}_{2}$ is shown in Figures 3(a) and 3 (b). The valence-band maximum $(\mathrm{VBM})$ value of $0.73 \mathrm{eV}$ for $\mathrm{NiO}$ is extrapolated from the $\mathrm{VB}$ spectrum using linear fitting. The VB spectrum for $\mathrm{TiO}_{2}$ was measured by similar a method as for $\mathrm{NiO}$ and is shown in Figure 3(b) and the VBM value of $0.73 \mathrm{eV}$ was observed. For $\mathrm{O} 1 \mathrm{~s}$ in the $\mathrm{NiO}$ sample, the less intense peak at a binding energy of $529.47 \mathrm{eV}$ corresponds to the $\mathrm{O} 1 \mathrm{~s}$ peak of $\mathrm{NiO}$. The very intense shoulder peak at $533.3 \mathrm{eV}$ is assigned to the surface adsorbed oxygen as shown in Figure 3(c). The $\mathrm{O} 1 \mathrm{~s}$ spectrum of $\mathrm{Ti}-\mathrm{O}$ is comprised on the two apparent peaks, one at $530.48 \mathrm{eV}$ is attributed to the $\mathrm{Ti}-\mathrm{O}$ bonds and the other at $532.21 \mathrm{eV}$ because of the surface adsorbed species as shown in Figure 3(d). The reported method [44] was used for the measurement of valence-band offset of $\mathrm{NiO} / \mathrm{TiO}_{2}$ heterojunctions by applying the following formula:

$$
\Delta E_{V}=\left(E_{\mathrm{Ni} 2 \mathrm{p}}^{\mathrm{NiO}}-E_{\mathrm{VBM}}^{\mathrm{NiO}}\right)-\left(E_{\mathrm{Ti} 2 \mathrm{p}}^{\mathrm{TiO}}-E_{\mathrm{VBM}}^{\mathrm{TiO}}\right)+\Delta E_{\mathrm{CL}} .
$$

Here $\left(E_{\mathrm{Ni} 2 \mathrm{p}}^{\mathrm{NiO}}-E_{\mathrm{VBM}}^{\mathrm{NiO}}\right)$ is the energy difference between $\mathrm{Ni}$ $2 \mathrm{p}$ and $\mathrm{VBM}$ in the pure $\mathrm{NiO}$ nanostructures, $\left(E_{\mathrm{Ti} 2 \mathrm{p}}^{\mathrm{TiO}}-E_{\mathrm{VBM}}^{\mathrm{TiO}}\right)$ is the energy difference between the Ti $2 \mathrm{p}$ and the VBM in the $\mathrm{TiO}_{2}$, and $\Delta E_{\mathrm{CL}}=\left(E_{\mathrm{Ti} 2 \mathrm{p}}^{\mathrm{TiO}}-E_{\mathrm{Ni} 2 \mathrm{p}}^{\mathrm{NiO}}\right)$ is the energy difference between the Ti $2 \mathrm{p}$ and $\mathrm{Ni} 2 \mathrm{p}$ core levels (CLs) in the $\mathrm{NiO} / \mathrm{TiO}_{2}$ 


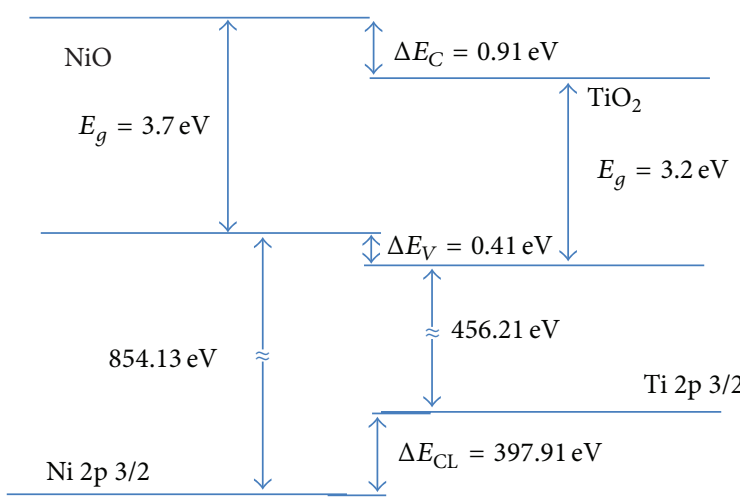

FIGURE 4: The schematic diagram of the band alignment.

heterostructures. Hence the measured valance-band offset of developed heterojunction is found to be $\sim 0.41 \mathrm{eV}$. The conduction-band offset of $\mathrm{NiO} / \mathrm{TiO}_{2}$ heterojunction was measured by the following formula:

$$
\Delta E_{C}=\left(E_{\text {band gap }}^{\mathrm{TiO}}-E_{\text {band gap }}^{\mathrm{NiO}}\right)-\Delta E_{V} .
$$

The respective band gap for the $\mathrm{NiO}$ is $3.7 \mathrm{eV}$ and $3.2 \mathrm{eV}$ for $\mathrm{TiO}_{2}$, respectively, at room temperature; thus the calculated $\Delta E_{C}$ is found to be $\sim 0.91 \mathrm{eV}$. However the schematic diagram of the band alignment is depicted in Figure 4. It can be observed that a type-II band alignment is produced at the junction of $\mathrm{NiO} / \mathrm{TiO}_{2}$ heterojunction. The observed ratio of $\mathrm{CBO}$ and $\mathrm{VBO} \Delta E_{C} / \Delta E_{V}$ is 2.21 .

\section{Conclusion}

In this study, the hydrothermal approach was used for the development of p-type $\mathrm{NiO} / \mathrm{n}$-type $\mathrm{TiO}_{2}$ heterojunction on the FTO glass substrate. The SEM and XRD techniques were used for the morphological and structural characterization. The XPS technique was used for the measurement of valenceband offset and the observed band offset was found to be $\sim 0.41 \mathrm{eV}$ and the conduction band of $\sim 0.91 \mathrm{eV}$ was determined. The ratio of conduction band and valence-band offset was found to be 2.21 .

\section{Conflict of Interests}

The authors declare that there is no conflict of interests regarding the publication of this paper.

\section{Acknowledgments}

This project was supported by King Saud University, Deanship of Scientific Research, and College of Science Research Centre.

\section{References}

[1] G. R. Patzke, F. Krumeich, and R. Nesper, "Oxidic nanotubes and nanorods anisotropic modules for a future nanotechnology," Angewandte Chemie-International Edition, vol. 41, no. 14, pp. 2446-2461, 2002.
[2] M. Grätzel, "Sol-gel processed $\mathrm{TiO}_{2}$ films for photovoltaic applications," Journal of Sol-Gel Science and Technology, vol. 22, no. 1-2, pp. 7-13, 2001.

[3] Z. X. Ge, A. X. Wei, J. Liu, W. Zhao, and C. B. Liu, "Synthesis and photovoltaic devices performance of single crystalline $\mathrm{TiO}_{2}$ nanowire bundle arrays," Journal of Inorganic Materials, vol. 25, no. 10, pp. 1105-1109, 2010.

[4] H. Chen, W. Y. Fu, H. B. Yang et al., "Photosensitization of $\mathrm{TiO}_{2}$ nanorods with CdS quantum dots for photovoltaic devices," Electrochimica Acta, vol. 56, no. 2, pp. 919-924, 2010.

[5] Y. K. Zhou, L. Cao, F. B. Zhang, B. L. He, and H. L. Li, "Lithium insertion into $\mathrm{TiO}_{2}$ nanotube prepared by the hydrothermal process," Journal of the Electrochemical Society, vol. 150, no. 9, pp. A1246-A1249, 2003.

[6] P. Charoensirithavorn, Y. Ogomi, T. Sagawa, S. Hayase, and S. Yoshikawa, "A facile route to $\mathrm{TiO}_{2}$ nanotube arrays for dyesensitized solar cells," Journal of Crystal Growth, vol. 311, no. 3, pp. 757-759, 2009.

[7] M. Anpo, "Preparation, characterization, and reactivities of highly functional titanium oxide-based photocatalysts able to operate under UV-visible light irradiation: approaches in realizing high efficiency in the use of visible light," Bulletin of the Chemical Society of Japan, vol. 77, no. 8, pp. 1427-1442, 2004.

[8] B. Q. Su, Y. J. Ma, Y. L. Du, C. Yang, and C. M. Wang, "In situ photoelectrocatalytic degradation behavior of methylene blue on $\mathrm{Nano}_{-} \mathrm{TiO}_{2}$ modified electrode," Journal of the Electrochemical Society, vol. 155, no. 10, pp. F213-F217, 2008.

[9] Y. Xie, "Photoelectrochemical application of nanotubular titania photoanode," Electrochimica Acta, vol. 51, no. 17, pp. 33993406, 2006.

[10] G. Yan, M. Zhang, J. Hou, and J. Yang, "Photoelectrochemical and photocatalytic properties of $\mathrm{N}+\mathrm{S}$ co-doped $\mathrm{TiO}_{2}$ nanotube array films under visible light irradiation," Materials Chemistry and Physics, vol. 129, no. 1-2, pp. 553-557, 2011.

[11] M. Zhang, J. Wu, J. Hou, and J. Yang, "Molybdenum and nitrogen co-doped titanium dioxide nanotube arrays with enhanced visible light photocatalytic activity," Science of Advanced Materials, vol. 5, no. 6, pp. 535-541, 2013.

[12] M. Zhang, J. Wu, D. Lu, and J. Yang, "Enhanced visible light photocatalytic activity for $\mathrm{TiO}_{2}$ nanotube array films by codoping with tungsten and nitrogen," International Journal of Photoenergy, vol. 2013, Article ID 471674, 8 pages, 2013.

[13] R. Ciancio, E. Carlino, C. Aruta, D. MacCariello, F. M. Granozio, and U. S. Di Uccio, "Nanostructure of buried interface layers in $\mathrm{TiO}_{2}$ anatase thin films grown on $\mathrm{LaAlO} 3$ and $\mathrm{SrTiO}_{3}$ substrates," Nanoscale, vol. 4, no. 1, pp. 91-94, 2012.

[14] S. Guo, S. Han, H. Mao et al., "Synthesis and characterization of nitrogen and phosphate codoped titanium dioxide with excellent visible-light photocatalytic activity," Journal of Alloys and Compounds, vol. 544, pp. 50-54, 2012.

[15] I. Lee, J. B. Joo, Y. Yin, and F. Zaera, “A yolk@shell nanoarchitecture for $\mathrm{Au} / \mathrm{TiO}_{2}$ catalysts," Angewandte Chemie-International Edition, vol. 50, no. 43, pp. 10208-10211, 2011.

[16] Y. P. Guo, N. H. Lee, H. J. Oh et al., "Preparation of titanate nanotube thin film using hydrothermal method," Thin Solid Films, vol. 516, no. 23, pp. 8363-8371, 2008.

[17] C. Suwanchawalit and S. Wongnawa, "Triblock copolymertemplated synthesis of porous $\mathrm{TiO}_{2}$ and its photocatalytic activity," Journal of Nanoparticle Research, vol. 12, no. 8, pp. 2895-2906, 2010. 
[18] A. Michailowski, D. Almawlawi, G. S. Cheng, and M. Moskovits, "Highly regular anatase nanotubule arrays fabricated in porous anodic templates," Chemical Physics Letters, vol. 349, no. 1-2, pp. 1-5, 2001.

[19] Y. S. Tian, C. G. Hu, X. S. He, C. L. Cao, G. S. Huang, and K. Y. Zhang, "Titania nanotube arrays for light sensor and UV photometer," Sensors and Actuators B, vol. 144, no. 1, pp. 203207, 2010.

[20] P. Xiao, D. Liu, B. B. Garcia, S. Sepehri, Y. Zhang, and G. Cao, "Electrochemical and photoelectrical properties of titania nanotube arrays annealed in different gases," Sensors and Actuators B, vol. 134, no. 2, pp. 367-372, 2008.

[21] W. Li, S. I. Shah, C. P. Huang, O. Jung, and C. Ni, "Metallorganic chemical vapor deposition and characterization of $\mathrm{TiO}_{2}$ nanoparticles," Materials Science and Engineering B, vol. 96, no. 3, pp. 247-253, 2002.

[22] B. Mukherjee, C. Karthik, and N. Ravishankar, "Hybrid solgel combustion synthesis of nanoporous anatase," Journal of Physical Chemistry C, vol. 113, no. 42, pp. 18204-18211, 2009.

[23] K. Kanie and T. Sugimoto, "Shape control of anatase $\mathrm{TiO}_{2}$ nanoparticles by amino acids in a gel-sol system," Chemical Communications, no. 14, pp. 1584-1585, 2004.

[24] H. Sato, T. Minami, S. Takata, and T. Yamada, "Transparent conducting p-type $\mathrm{NiO}$ thin films prepared by magnetron sputtering," Thin Solid Films, vol. 236, no. 1-2, pp. 27-31, 1993.

[25] X. C. Lou, X. J. Zhao, and X. He, "Boron doping effects in electrochromic properties of $\mathrm{NiO}$ films prepared by sol-gel," Solar Energy, vol. 83, no. 12, pp. 2103-2108, 2009.

[26] H. Steinebach, S. Kannan, L. Rieth, and F. Solzbacher, " $\mathrm{H}_{2}$ gas sensor performance of $\mathrm{NiO}$ at high temperatures in gas mixtures," Sensors and Actuators B, vol. 151, no. 1, pp. 162-168, 2010.

[27] M. A. Abbasi, Z. H. Ibupoto, M. Hussain et al., "Potentiometric zinc ion sensor based on honeycomb-like $\mathrm{NiO}$ nanostructures," Sensors, vol. 12, no. 11, pp. 15424-15437, 2012.

[28] Z. Zhang, C. Shao, X. Li, C. Wang, M. Zhang, and Y. Liu, "Electrospun nanofibers of p-type $\mathrm{NiO} / \mathrm{n}$-type $\mathrm{ZnO}$ heterojunctions with enhanced photocatalytic activity," ACS Applied Materials and Interfaces, vol. 2, no. 10, pp. 2915-2923, 2010.

[29] C. Shifu, Z. Sujuan, L. Wei, and Z. Wei, "Preparation and activity evaluation of p-n junction photocatalyst $\mathrm{NiO} / \mathrm{TiO}_{2}$," Journal of Hazardous Materials, vol. 155, no. 1-2, pp. 320-326, 2008.

[30] Y. Ku, C. N. Lin, and W. M. Hou, "Characterization of coupled $\mathrm{NiO} / \mathrm{TiO}_{2}$ photocatalyst for the photocatalytic reduction of $\mathrm{Cr}(\mathrm{VI})$ in aqueous solution," Journal of Molecular Catalysis A, vol. 349, no. 1-2, pp. 20-27, 2011.

[31] Y. Chen, J. C. Crittenden, S. Hackney, L. Sutter, and D. W. Hand, "Preparation of a novel $\mathrm{TiO}_{2}$-based p-n junction nanotube photocatalyst," Environmental Science and Technology, vol. 39, no. 5, pp. 1201-1208, 2005.

[32] J. L. Chung, J. C. Chen, and C. J. Tseng, "Preparation of $\mathrm{TiO}_{2}$ doped $\mathrm{ZnO}$ films by radio frequency magnetron sputtering in ambient hydrogen-argon gas," Applied Surface Science, vol. 255, no. 5, pp. 2494-2499, 2008.

[33] J. K. Kang and S. W. Rhee, "Chemical vapor deposition of nickel oxide films from $\mathrm{Ni}\left(\mathrm{C}_{5} \mathrm{H}_{5}\right)_{2} / \mathrm{O}_{2}$," Thin Solid Films, vol. 391, no. 1, pp. 57-61, 2001.

[34] K. Zheng, L. Gu, D. Sun, X. Mo, and G. Chen, "The properties of ethanol gas sensor based on Ti doped $\mathrm{ZnO}$ nanotetrapods," Materials Science and Engineering B, vol. 166, no. 1, pp. 104-107, 2010.
[35] B. A. Reguig, A. Khelil, L. Cattin, M. Morsli, and J. C. Bernède, "Properties of $\mathrm{NiO}$ thin films deposited by intermittent spray pyrolysis process," Applied Surface Science, vol. 253, no. 9, pp. 4330-4334, 2007.

[36] R. G. S. Pala, W. Tang, M. M. Sushchikh et al., "CO oxidation by $\mathrm{Ti}$ - and Al-doped ZnO: oxygen activation by adsorption on the dopant," Journal of Catalysis, vol. 266, no. 1, pp. 50-58, 2009.

[37] R. Deng, B. Yao, Y. F. Li et al., "X-ray photoelectron spectroscopy measurement of $\mathrm{n}-\mathrm{ZnO} / \mathrm{p}-\mathrm{NiO}$ heterostructure valence-band offset," Applied Physics Letters, vol. 94, no. 2, Article ID 022108, 2009.

[38] Y. Ishida, A. Fujimori, H. Ohta, M. Hirano, and H. Hosono, "Potential profiling of the nanometer-scale charge-depletion layer in $\mathrm{n}-\mathrm{ZnO} / \mathrm{p}-\mathrm{NiO}$ junction using photoemission spectroscopy," Applied Physics Letters, vol. 89, no. 15, Article ID 153502, 2006.

[39] H. Long, G. J. Fang, H. H. Huang et al., "Ultraviolet electroluminescence from $\mathrm{ZnO} / \mathrm{NiO}$-based heterojunction light-emitting diodes," Applied Physics Letters, vol. 95, no. 1, Article ID 013509, 2009.

[40] P. Zurcher and R. S. Bauer, "Photoemission determination of dipole layer and VB-discontinuity formation during the MBE growth of GaAs on Ge(110)," Journal of Vacuum Science and Technology A, vol. 1, no. 2, pp. 695-700, 1982.

[41] W. Göpel, J. A. Anderson, D. Frankel et al., "Surface defects of $\mathrm{TiO}_{2}(110)$ : a combined XPS, XAES AND ELS study," Surface Science, vol. 139, no. 2-3, pp. 333-346, 1984.

[42] S. Pétigny, H. Mostéfa-Sba, B. Domenichini, E. Lesniewska, A. Steinbrunn, and S. Bourgeois, "Superficial defects induced by argon and oxygen bombardments on (110) $\mathrm{TiO}_{2}$ surfaces," Surface Science, vol. 410, no. 2-3, pp. 250-257, 1998.

[43] S. A. Bilmes, P. Mandelbaum, F. Alvarez, and N. M. Victoria, "Surface and electronic structure of titanium dioxide photocatalysts," Journal of Physical Chemistry B, vol. 104, no. 42, pp. 98519858, 2000.

[44] S. H. Wei and A. Zunger, "Calculated natural band offsets of all II-VI and III-V semiconductors: chemical trends and the role of cation d orbitals," Applied Physics Letters, vol. 72, no. 16, pp. 2011-2013, 1998. 

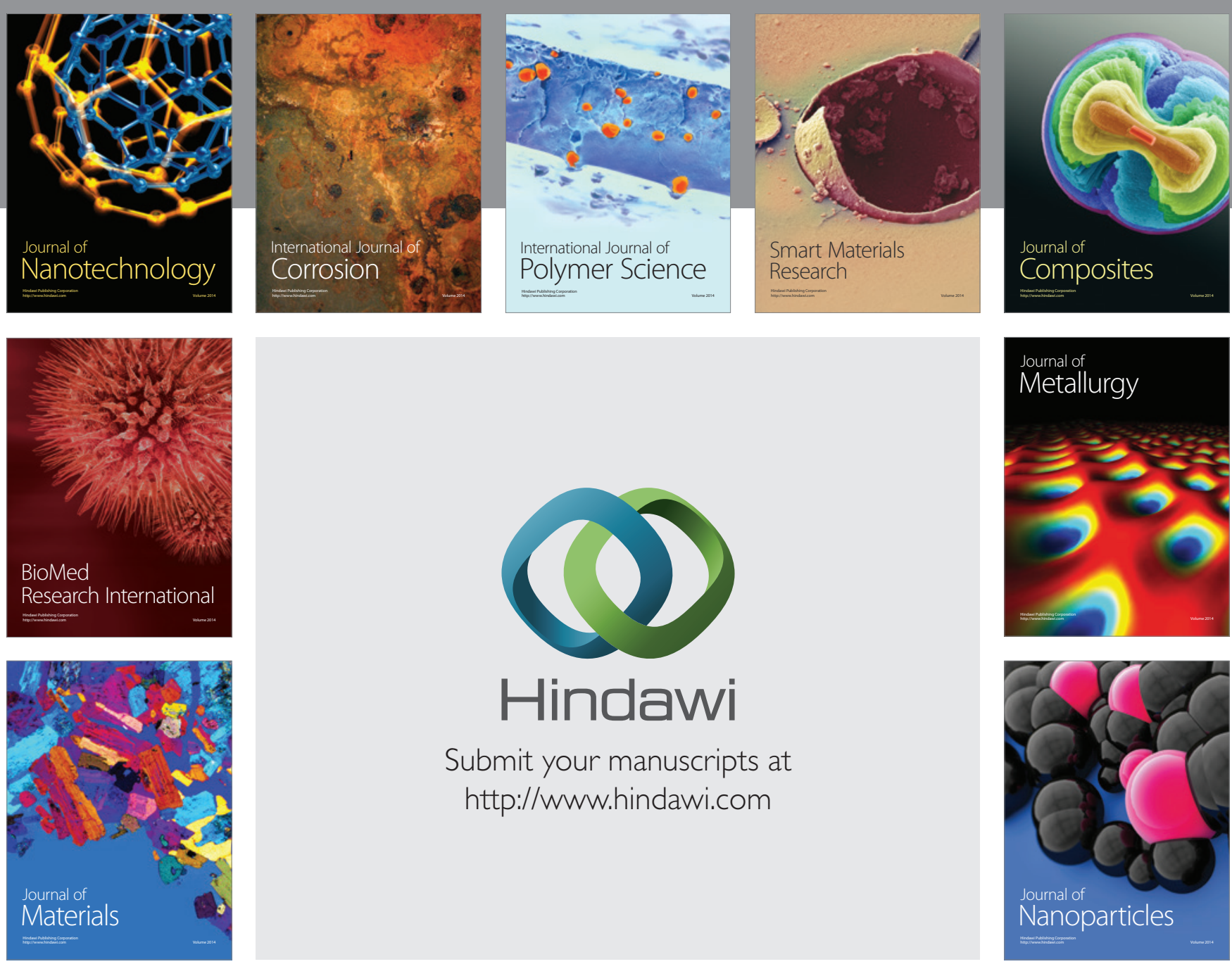

Submit your manuscripts at http://www.hindawi.com
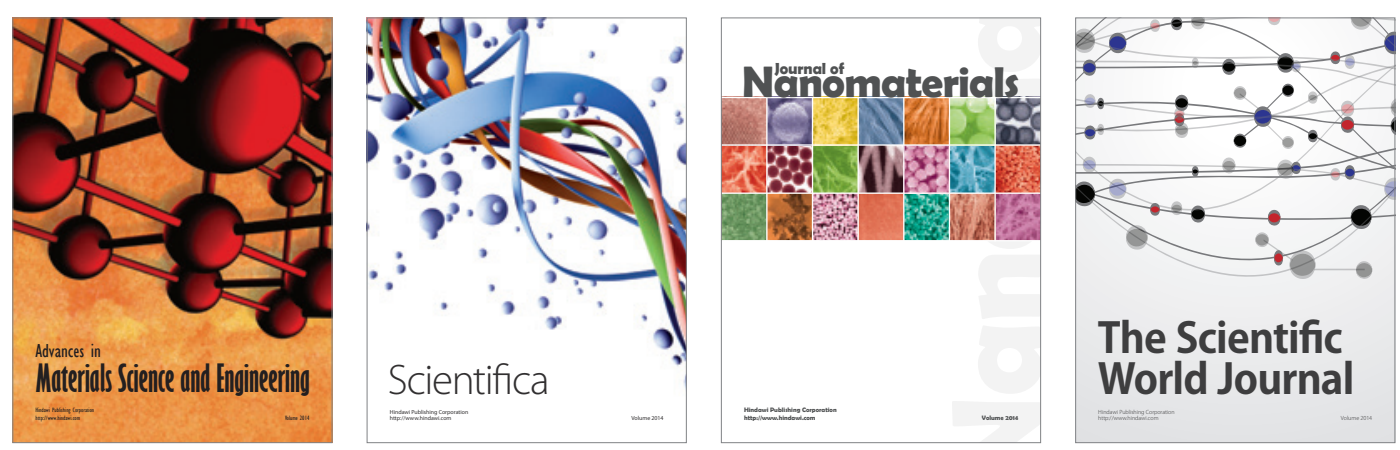

\section{The Scientific World Journal}
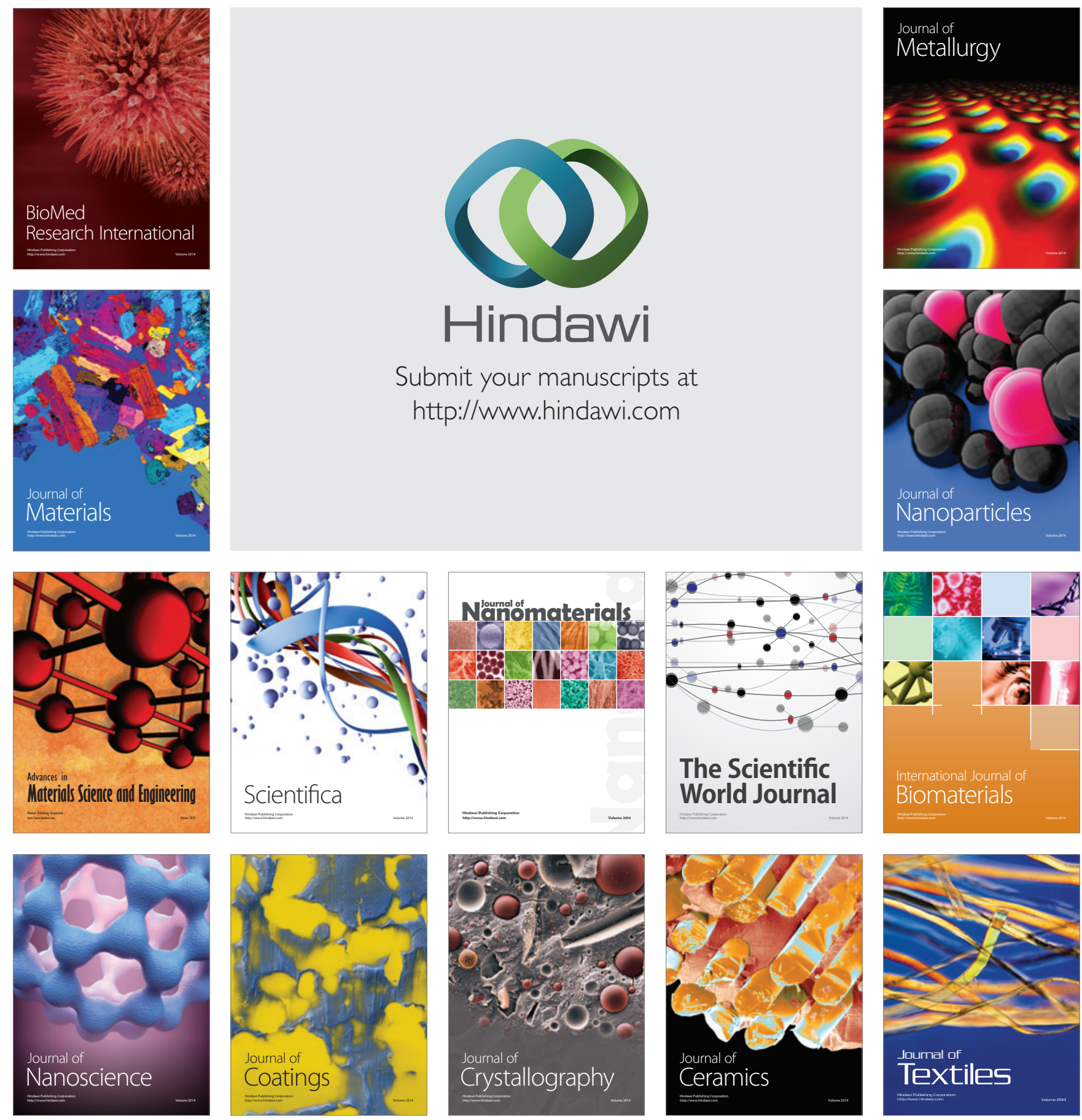